\title{
Quantifying Urban Unemployment Rate: Challenges, Coping Mechanisms and Self Employment Trends in Ethiopian Urban Centers
}

\author{
Efa Tadesse Debele \\ Department of Sociology, College of Social Sciences, Addis Ababa University, Addis Ababa, Ethiopia
}

Email address:

efatdss@gmail.com

\section{To cite this article:}

Efa Tadesse Debele. Quantifying Urban Unemployment Rate: Challenges, Coping Mechanisms and Self Employment Trends in Ethiopian Urban Centers. International and Public Affairs. Vol. 4, No. 2, 2020, pp. 44-52. doi: 10.11648/j.ipa.20200402.14

Received: August 13, 2019; Accepted: October 15, 2019; Published: September 10, 2010

\begin{abstract}
Currently, urban unemployment is alarming with drastic scenario. In this regard urban areas area highly affected by unemplyments. For this problem several factors are assumed to be in charge. These factors themselves vary from place to place. Urban areas occupied by numerous residents. Those residents are mainly jobseekers. Urban unemployment touches enormous issues include difficulties related to joblessness, system of dealing with such difficulties, entrepreneurship or self employment tendencies and complexity of the patterns of urban unemployment problems. However, the challenges, coping mechanisms, self employment trends and patterns of urban unemployment issues were not well examined and analyzed. Therefore, in this research those gaps were considered and key findings were realized. This research utilized quantitative data source and quantitative research methods were employed. Statistical packages for social sciences (SPSS) version 20 software was utilized for both descriptive and inferential statistics. In fact, socio-demographic characteristics of respondents such as sex, educational categories and marital status were examined. Furthermore, variables, which potentially predict urban unemployment rate, were sufficiently quantified. Association and regression analysis was done for patterns of urban unemployment that help to identify determinants of urban unemployment. So this article was supposed to fill previous gaps concerning quantification of urban unemployment and its patterns.
\end{abstract}

Keywords: Urban Unemployment, Challenges, Coping Mechanisms, Self Employment Rate

\section{Introduction}

Nowadays, urban growth creates both opportunities and challenges for its residents. Even though, urban social evils are countless the urban unemployment is predominant otherwise demanding issue. There are several factors aggravate urban unemployment that need rigorous investigation. Thus, this research aims at uncovering those underlying causes of urban unemployment and associated challenges as well as coping mechanisms.

Urban unemployment rate demands accurate measurement that is why I decided to look at its magnitude at national level. Of course, quantifying urban unemployment requires appropriate data and correct measurement which should be backed by logic and rigorous study as well as systematized empirical observation. For that reason, I took data from CSA in order to conduct genuine research. Indeed, I found the raw data very relevant and it was gathered with full of caution. Furthermore, I concerned about urban unemployment problems because of its urgency and seriousness in Ethiopia. Therefore, its accomplishment was expected to impact the existing urban policy by providing practical and effective recommendations on urban unemployment problems. In nut shell, this research was supposed to address the following key research Objectives;

1. To describe the overall socio-demographic characteristics of respondents

2. To identify problems associated with urban unemployment

3. To examine challenge and coping mechanisms related to urban unemployment

4. To analyze patterns of variables associated with urban 
unemployment rates

\section{Methodology}

The basic data for this urban unemployment analysis was the raw data or survey done by statistics agency on urban unemployment in 2018 which I found relevant research problem in present urban development context. Of course, I chose Quantitative research method that I believe it can help me to address the problem very well. For that reason, I took data from CSA by assuming this data is vital to understand the extent of the problem. In fact, the data checked for analysis and then I run the SPSS version 20 software for analyzing the variables associate with urban unemployment problems. In view of that I employed both descriptive and inferential statistics. Accordingly, frequencies, percentages, tables, graphs, measure of association or gamma value, chisquare test and association analysis or regression analysis were utilized in this research in line with the research objectives.

\section{Results and Discussion}

\section{Socio-demographic Characteristics of Respondents}

Sex

The description of sex of respondents has been identified and the detail of this finding as organized in table 1 indicated that $46.9 \%$ of the respondents were male and $53.1 \%$ of respondents were females. This may possibly depict that the given population is female dominated. The more female number can suggest that females are more likely to confine at urban centers and they are also the most vulnerable group in terms of unemployment. Women are subject to higher risk of unemployment when compared with men (Bicakova, 2010) [1]. In fact, females are more likely to pursue adapt strategy via moving away from home.

Table 11. Distribution of sex of respondents.

\begin{tabular}{llllll}
\hline Sex & & Frequency & Percent & Valid Percent & Cumulative Percent \\
\hline \multirow{3}{*}{ Valid } & Male & 32733 & 46.9 & 46.9 & 46.9 \\
& Female & 37017 & 53.1 & 53.1 & 100.0 \\
& Total & 69750 & 100.0 & 100.0 & \\
\hline
\end{tabular}

Source: Computed from CSA survey, 2018.

\section{Literacy Status}

Educational status of the respondents has been uncovered that more or less respondents are literate. See table 2 that confirms the number of educated people are more than illiterate $(16.2 \%)$ of the sample while the majority of respondents $(72.3 \%)$ found to be educated. Thus, the urban unemployment becomes predominantly outweighed by educated. [2] In line with this Poschke (2018) found that self employment rate and their unemployment rates patterns differ by education group. The untrained more likely engage in minor an activity that does not require profession and illiterate do everything supposed to generate income regardless of job status.

Table 22. Distribution of literacy status of respondents.

\begin{tabular}{llllll}
\hline Literacy & & Frequency & Percent & Valid Percent & Cumulative Percent \\
\hline \multirow{3}{*}{ Valid } & Yes & 50457 & 72.3 & 81.7 & 81.7 \\
& No & 11328 & 16.2 & 18.3 & 100.0 \\
Missing & Total & 61785 & 88.6 & 100.0 & \\
Total & System & 7965 & 11.4 & & \\
\hline
\end{tabular}

Source: Computed from Survey by CSA, 2018.

\section{Marital Status}

Marital status of the respondents has been uncovered that more or less respondents from urban unemployed are never married. See graph 1 that substantiates the number of never married people are $46.73 \%$ of the sample while the married respondents consists of $40.96 \%$ and the remaining found to be divorced, widowed, separate and live together. Thus, the single individuals become easy to be prone to the problems of the urban unemployment. [3] In this regard Broussard, C, Anne et al. (2012) asserts singles are more likely vulnerable than their counterparts by suffering from downsides of unemployment. Singles are the most likely to be unemployed and less likely to be employers (Earle et al, 2000) [4]. The married more likely survive from downsides of urban unemployment by assistance from spouses. Married women obtained their status through their men's job (Meer, 2014) [5]. Furthermore, young unemployment is even worse than the overall unemployment rate (Ayres, 2013) [6]. 


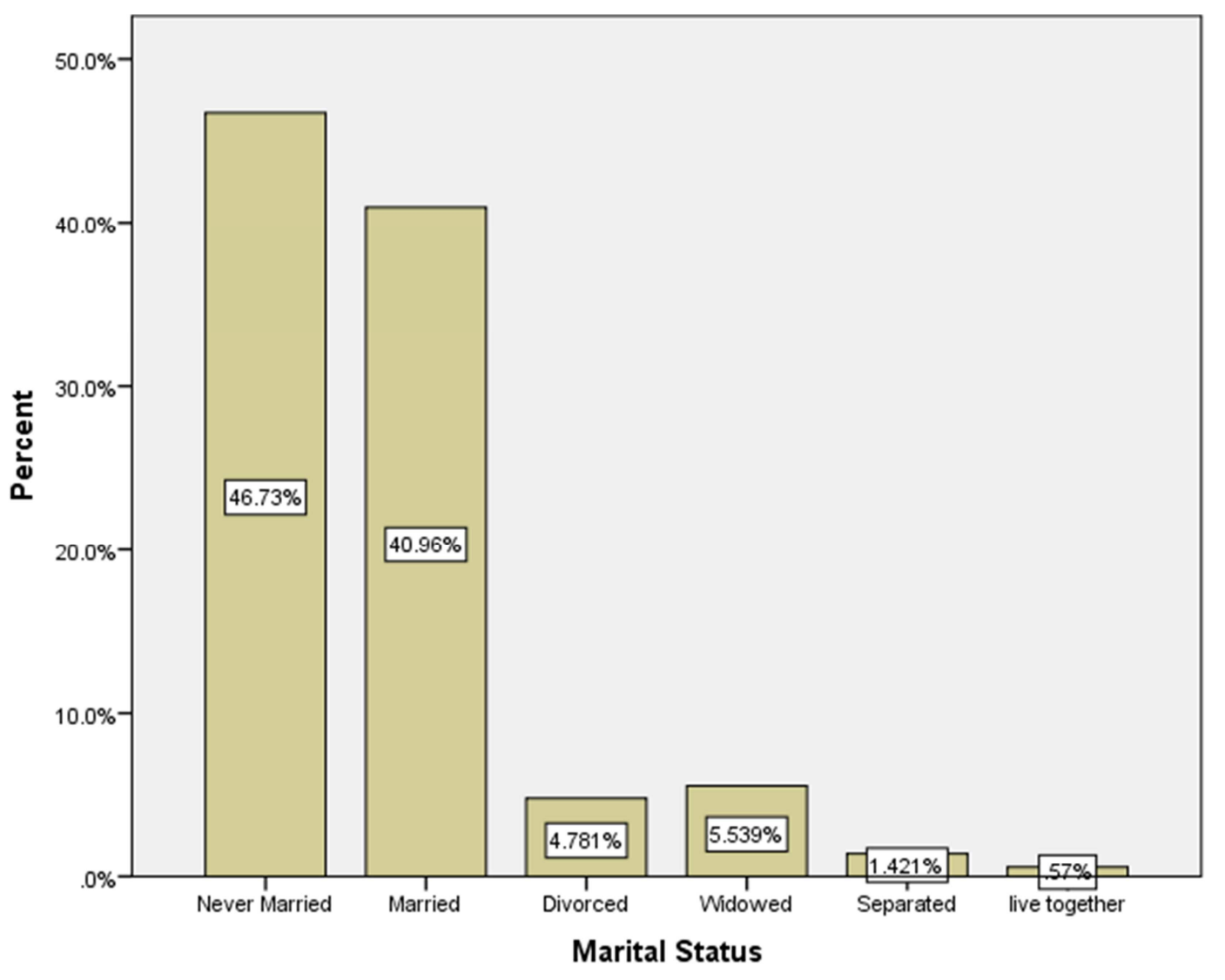

Source: Computed from CSA survey, 2018.

Figure 11. Description of marital status of respondents.

\section{Problems Associate with Urban Unemployment}

\subsection{Reasons Not to Start Businesses}

The respondents' business engagement scenario from graph 2 depicts that $54.81 \%$ of the sample respondents reported that their reason not to engage in business is shortage of finance and $14.91 \%$ of them reported that their reason not to start businesses are lack of work places and finance. Earle et al (2000) states that financial constraints are more important determinant of self employment. The remaining respondents told that they had problem of training, lack of land / place of work, lack of licenses, shortage of equipment, lack of information and lack of support from family. This demonstrates that the motivation of job seekers to start businesses is to some extent good if the preconditions are available. It seems that absence of finance and work place constrained them to suffer from problems of joblessness. They also lack information and business skill as well as support from their relatives. In this regard, Job seekers, who work cooperatively with relatively richer households that can afford all necessary preconditions, are more likely engage in business or self-employment. On the other hand, the job seeker that lacked the above privileges used to pursue wandering. Intervention should be taken to check the fairness of markets in order to make sure that disadvantaged urban groups become beneficiaries (Debele, 2019, pp. 259) [7]. In addition, John et al (2006) reports that urban poverty cause urban unemployment rate [8].

\subsection{Reasons Not to Find Employment}

Statistical evidences as it can be seen from graph 3 illustrates that around more than half of the sample households $(55.61 \%)$ reported that their reasons not to find employment was lack of job opportunity and the remaining respondents responded that they had no training, absence of professions related to work, lack of experience, absence of vacancies, new systems of work, searching better work, dislike distance working place, dislike low payments, inconvenience of time and the like. This illustrates that the absence of job opportunity was main reasons not to employments. The job opportunity does not become available as urban growth increases as imagined (Debele, 2017) $[9,10]$ In line with this (Poschke, 2018) mentioned that reasons for unemployment are high and job finding is low in Ethiopia. 


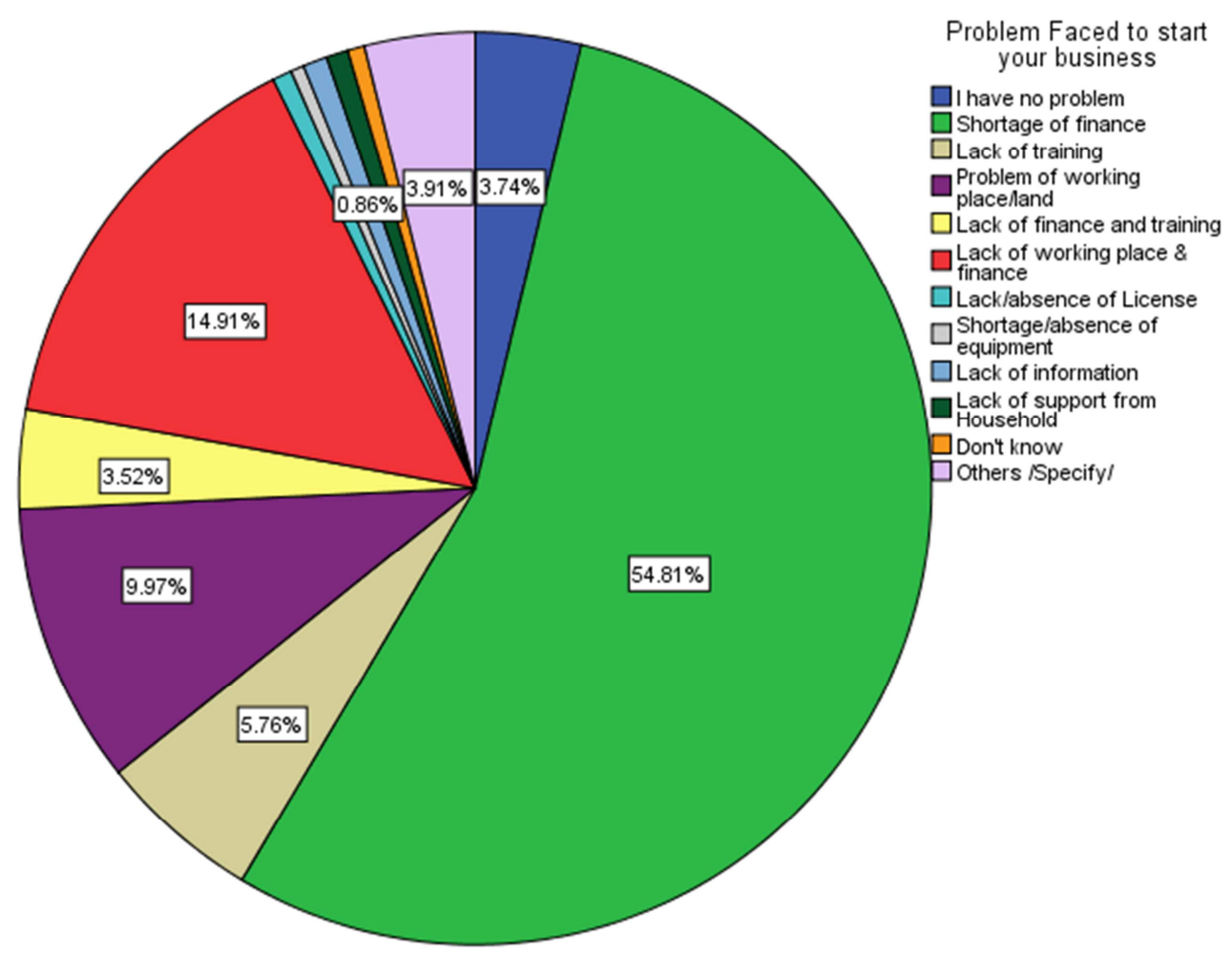

Source: Computed from CSA survey, 2018.

Figure 22. Description of problems related to starting business.

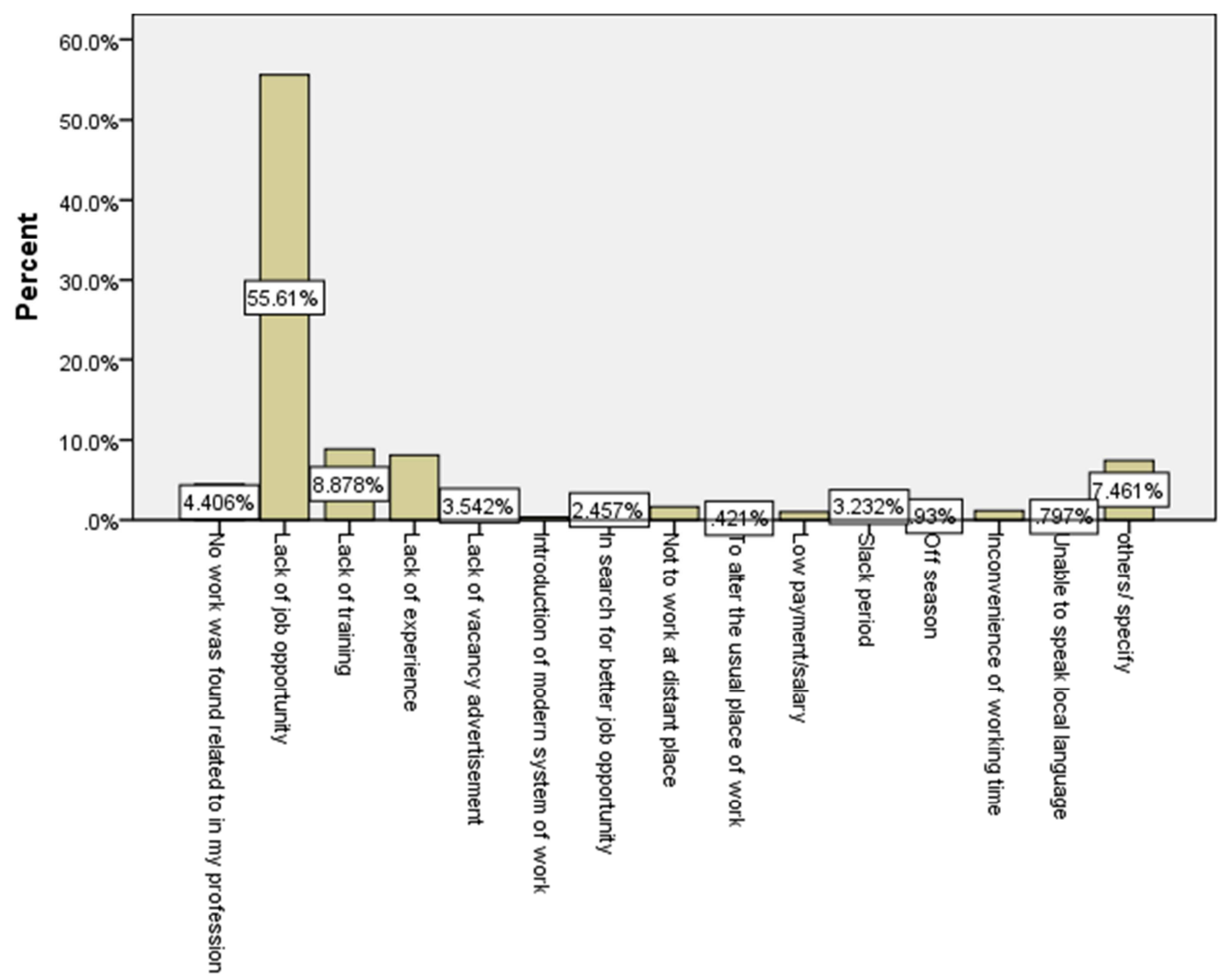

What was the Main Reason for not found Employment?

Source: Computed from CSA survey, 2018.

Figure 33. Description of reasons related to unemployment of respondents. 


\section{Challenges of Urban Unemployment and Coping Mechanisms}

\subsection{Major Challenges Related to Joblessness}

It is possible to observe from graph 4 that decreased household or personal income was main challenge which share $43.52 \%$ of the challenges related to joblessness whereas $21.23 \%$ of respondents replied that the inability to cover household expenses and the remaining reported that inability to send their children to school, family dissolution, getting stress, hopelessness, exposed to different addictions, hunger and lack of clothing, isolated from social participation, wandering for jobs, etc. [11] In line with this Shita, et al (2018) stated that main reason of urban unemployment is shortage of vacancies. These challenges of urban unemployment were the effects of the economically imposed pressures up on the urban jobless that aim at dehumanizing the job seekers just to deny their potential and human dignity via labor exploitation and market monopolization by economic power elites. Despite the tremendous homogeneity existed in the jobless, few of the jobless used to adjust themselves via different mechanisms like dependence on their family assistance.

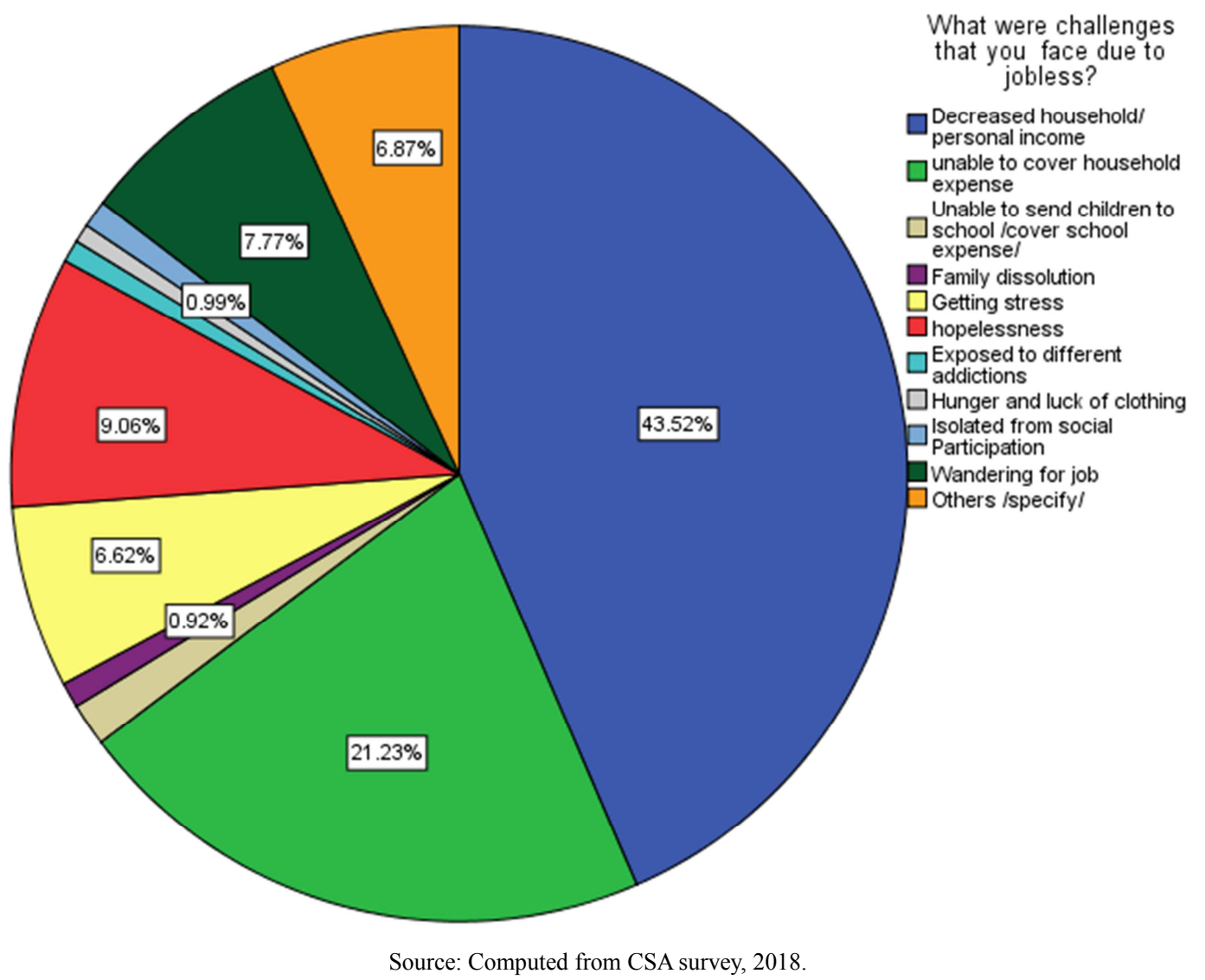

Figure 44. Description of challenges associated with joblessness.

\subsection{Mechanisms to Support Oneself}

The data from graph 5 clearly indicates that the majority of the respondents or $84.37 \%$ reported that their mechanisms to support themselves via family supports whereas only $2.5 \%$ respondents expressed their opinion that they have casual work and the remaining said support from relatives and friends, saving, remittance, begging, etc as their coping mechanisms to support themselves. Relatively job seekers living with the family home have more probability to save their economic expenditure due to better living cost. These job seekers can save moneys thereby minimizing the economic vulnerability. Furthermore, they can promote their productivity and engage in the businesses thereby advancing their economic gain. [12] In line with this Lorenzini, J and
Giugni, M (2010) stressed that family support reduce financial difficulties and provide assistance in finding a job. Such privileges strengthen their economic capacity so that it enables job seeker to be self sufficient at least in food. On the contrary, the job seekers living remote from family area lack adequate money otherwise no money to survive. This weakens their economic capacity in order not to progress. Thus, such job seekers always look out for basic needs and other demands. Moreover, they are unable to adapt the goods' price inflation since they are incapable to meet economic affordability. As a result, the majority of the job seekers are obliged to be economically marginalized and become unproductive citizens. 


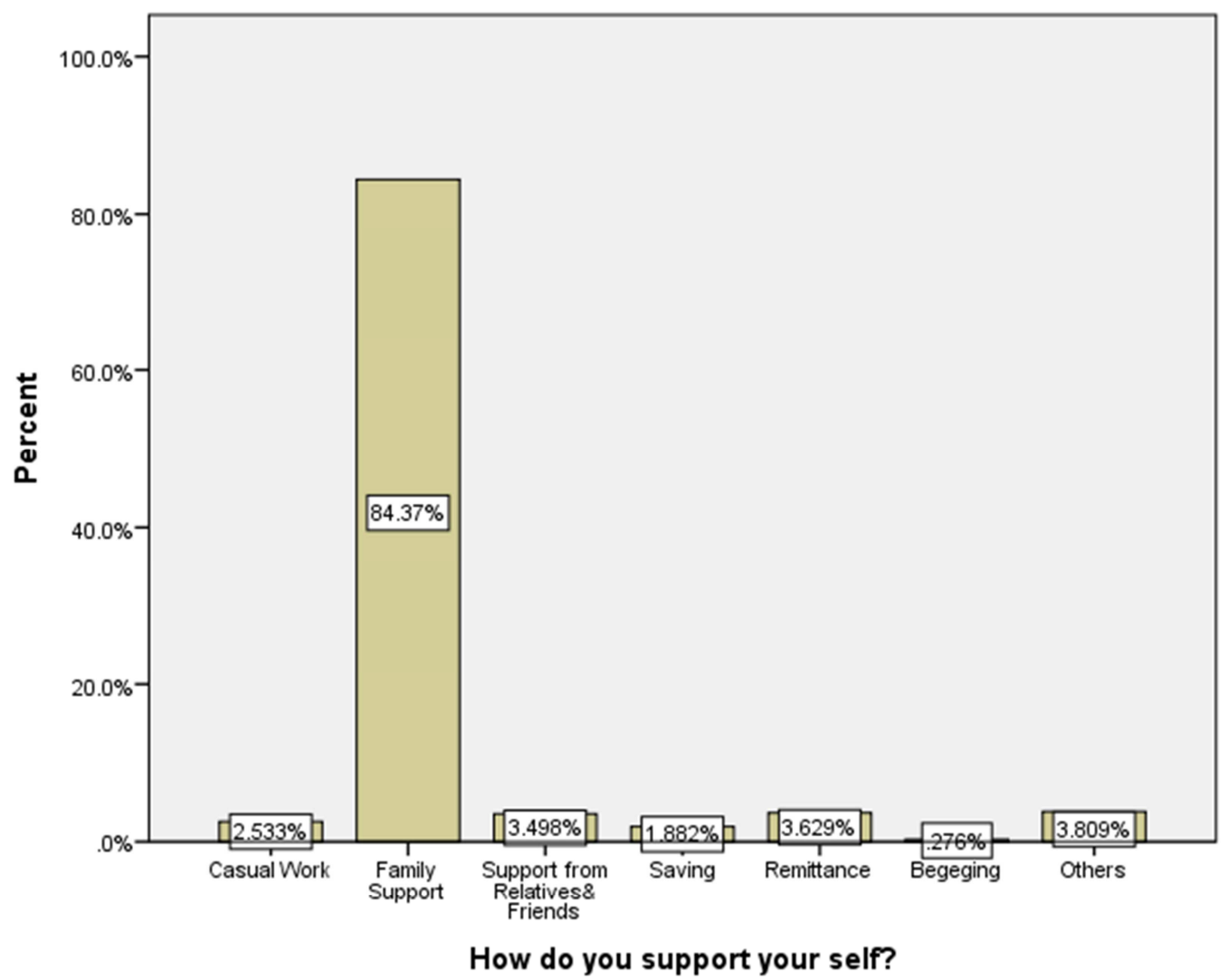

Source: Computed from CSA survey, 2018.

Figure 55. Description of mechanisms to support oneself.

\section{Testing Patterns Between Variables}

\subsection{Cross Tabulation of Urban Self-unemployment Rate by Gender of Respondents}

The measure of association was executed in table 3 on the next page to determine the association between the reasons not to start businesses or lack of self-employment and gender difference. Thus,

Ho: There is no association between reasons of self unemployment and gender difference

H1: There are relationships between reasons of selfunemployment and gender difference

In view of that the hypothesis of independence (null) is disproved since chi-square is greater than value at eleven degree of freedom (30.680> 19.675), gamma value is 0.045 and significance value ( $\mathrm{p}$-value) is 0.000 which is less than alpha $(0.000<0.05)$ and phi coefficient is 0.115 . This indicates that the chi-square statistic of association is significant at the $5 \%$ level. That means, it is a sufficient evidence to accept alternative hypothesis and infer the selfunemployment and gender difference have associations.

In addition to this, it can be clearly seen from table 3 (next page) that $75.3 \%$ or greater number of females associated with shortages of finance and lack of working place which is key indicators of self-employment barriers and only $24.7 \%$ of males' self-unemployment impacted by business barriers.
This figure clearly indicates that the number of females is greater than males by having more problems to start businesses. Females are more likely to face challenges to start businesses. This is may be due to female's lack of daring to encounter bureaucratic constraints while finding funding. They are less assertive compared with males. Females also prefer marriage instead of insisting on self employment. But, males more likely encounter bureaucratic challenges. Self entrepreneurship is also not incorporated in academia. This implies entrepreneurship challenges are more likely severe on majority job seekers or females than males. But, if such challenges removed and financial opportunity and other preconditions are available than females' aspiration also increase to engage in business and make a difference. Statistically speaking, one unit increase in females' aspiration to engage in business causes an increment of urban selfemployment by $11.5 \%$ (from symmetric measure, phi coefficient) other factors remain constant. In other word, one unit supply in business opportunity rises the demand of business by females. [13] In line with this Vipond (1984) stated that personal characteristic of job seekers such as sex considered as main determinants of urban unemployment rate. Certain variations in female self unemployment results in changes of overall urban self-unemployment. This indicates that urban self unemployment rate differs by gender difference. 
Table 33. Cross tabulation of urban self-unemployment $*$ sex of respondents.

\begin{tabular}{|c|c|c|c|}
\hline \multirow{2}{*}{ Problem Faced to start your business } & \multicolumn{2}{|l|}{ Sex } & \multirow{2}{*}{ Total } \\
\hline & Male & Female & \\
\hline I have no problem & 14 & 73 & 87 \\
\hline Shortage of finance & 343 & 933 & 1276 \\
\hline Lack of training & 35 & 99 & 134 \\
\hline Problems of working place/land & 39 & 193 & 232 \\
\hline Lack of finance and training & 25 & 57 & 82 \\
\hline Lack of working place $\&$ finance & 69 & 278 & 347 \\
\hline Lack/absence of License & 6 & 10 & 16 \\
\hline Shortage/absence of equipment & 2 & 9 & 11 \\
\hline Lack of information & 5 & 15 & 20 \\
\hline Lack of support from Household & 1 & 17 & 18 \\
\hline Don't know & 6 & 8 & 14 \\
\hline Other /Specify/ & 29 & 62 & 91 \\
\hline Total & 574 & 1754 & 2328 \\
\hline
\end{tabular}

Chi-Square Tests

\begin{tabular}{llll}
\hline & Value & Degree of freedom & Asymptote Significance (2-sided) \\
\hline Pearson Chi-Square & $30.680^{\mathrm{a}}$ & 11 & .001 \\
Likelihood Ratio & 32.387 & 11 & .001 \\
Linear-by-Linear Association & .046 & 1 & .830 \\
N of Valid Cases & 2328 & & \\
\hline
\end{tabular}

Symmetric Measures

\begin{tabular}{|c|c|c|c|c|c|}
\hline & & Value & Asymptote Standard deviation Error & Approximate & Approx. Significance \\
\hline \multirow{3}{*}{ Nominal by Nominal } & Phi & .115 & & & .001 \\
\hline & Cramer's V & .115 & & & .001 \\
\hline & Contingency Coefficient & .114 & & & .001 \\
\hline Ordinal by Ordinal & Gamma & .045 & .039 & 1.160 & .246 \\
\hline $\mathrm{N}$ of Valid Cases & & 2328 & & & \\
\hline
\end{tabular}

Source: computed from CSA survey, 2018.

\subsection{Urban Unemployment Rate by Literacy Rate}

The degree of unemployment rate can be influenced by several factors. One of the patterns upset unemployment rate is the literacy rate. So, my research question: Is there differences of literate and illiterate on urban unemployment rate or does unemployment rates differ by literacy rate.

$\mathrm{Ho}=0$, There is differences between literate and illiterate

Ho $\neq 0$, There is no difference between literate and illiterate

The measures of association or independence were executed in table 4 (next page) to determine the association between the extent of urban unemployment and literacy status. Accordingly, hypothesis of independence $(\mathrm{Ho} \neq 0)$ rejected since chi-square is greater than critical value at fourteen degree of freedom $(73.380>23.685)$, gamma value is 0.08 which is differ from zero and significance value or $\mathrm{p}$ value is 0.010 which is less than alpha $(0.010<0.05)$ and phi coefficient is 0.127 . This indicates chi-square statistic of association is significant at the $5 \%$ level. This shows reasons not to found employment and literacy difference of respondents are significantly associated that further shows unemployment rate and literacy rate are not independent to each other that results in rejecting alternatives hypothesis. This asserts literate group more likely associates with urban unemployment and illiterates are less likely suffer from urban unemployment. Literate group most often wanders for vacancy in steady of doing small businesses. In line with this A. S, Bakare (2011) reported that education and training system which de-emphasizes self employment can provoke unemployment. But, illiterate group does engage in every activity disregarding job status. Literate group search for field related job and degree level payment. In fact, the number of literate is also greater in urban that are substantively significant numbers. Furthermore, Literate usually ashamed of doing minor or so called silly works such as shoeshine, small businesses, loading items, driving, domestic works and et cetera which usually done by illiterates. [14] In line with this (A D Tombolotutu et al, 2018) reports upgrading informal can reduce poverty and unemployment rate. [15] However, Young (2012) found that literate is less likely unemployed compared to illiterate or uneducated whereas US department of commerce (2018) [16] found unemployment and educational level has strong relationship. From this research it was discovered that literacy and urban unemployment rate increase concomitantly. Statistically speaking, one unit increase in literacy rate can cause $12.7 \%$ (from symmetric measures, phi coefficient) increase in urban unemployment rates other factors remain constant.

Additionally, the data in table 4 indicate that more than three fourth $(88 \%)$ of literate associated with urban unemployment rate and only $20 \%$ of illiterate associates with urban unemployment. This implies that in urban unemployment literate individuals more likely suffer from problems related to joblessness. In this regard, the illiterate in the urban engage in minor activities and they are also 
minorities in urban due to high literacy rate.

Table 44. Cross tabulation urban unemployment * literacy status of respondents.

\begin{tabular}{llll}
\hline What was the Main Reason for not found Employment? Urban & \multicolumn{2}{l}{ Can You Read and Write? Literacy rate condition } & \multirow{2}{*}{ Total } \\
\cline { 2 - 4 } unemployment rate & Yes & No & 199 \\
\hline No work was found related to in my profession & 192 & 7 & 2512 \\
Lack of job opportunity & 2207 & 66 & 401 \\
Lack of training & 335 & 26 & 367 \\
Lack of experience & 341 & 3 & 160 \\
Lack of vacancy advertisement & 157 & 1 & 17 \\
Introduction of modern system of work & 16 & 10 & 111 \\
In search for better job opportunity & 101 & 17 & 73 \\
Not to work at distant place & 56 & 2 & 19 \\
To alter the usual place of work & 17 & 9 & 45 \\
Low payment/salary & 36 & 30 & 146 \\
Slack period & 116 & 8 & 42 \\
Off season & 34 & 4 & 52 \\
Inconvenience of working time & 48 & 5 & 36 \\
Unable to speak local languages & 31 & 49 & 337 \\
Others / specify & 288 & 542 & 4517 \\
\hline
\end{tabular}

Chi-Square Tests

\begin{tabular}{llll}
\hline & Value & Degree of freedom & Asymptote Significance (2-sided) \\
\hline Pearson Chi-Square & $73.380^{\mathrm{a}}$ & 14 & .000 \\
Likelihood Ratio & 82.454 & 14 & .000 \\
Linear-by-Linear Association & 7.427 & 1 & .006 \\
N of Valid Cases & 4517 & & \\
\hline
\end{tabular}

Symmetric Measures

\begin{tabular}{|c|c|c|c|c|c|}
\hline & & Value & Asymptote Standard deviation Error & Approximate & Approx. Significance. \\
\hline \multirow{3}{*}{ Nominal by Nominal } & Phi & .127 & & & .000 \\
\hline & Cramer's V & .127 & & & .000 \\
\hline & Contingency Coefficient & .126 & & & .000 \\
\hline Ordinal by Ordinal & Gamma & .083 & .035 & 2.311 & .021 \\
\hline $\mathrm{N}$ of Valid Cases & & 4517 & & & \\
\hline
\end{tabular}

Source: computed from CSA survey, 2018.

\section{Conclusion}

In this quantitative research I employed both descriptive and inferential statistics and proved that both of them play pivotal roles in quantifying and analyzing urban unemployment problems. In view of that from the above study it is discovered that urban unemployment is predominantly associated with numbers of females, literate group and unmarried group. Furthermore, it was revealed that urban job seekers suffer from urban unemployment problems in pursuing starting business or self-employment and finding employment. In fact, jobless individuals encounter several challenges in urban and they use different coping mechanisms to support themselves. The patterns among variables associated with urban unemployment tested and it was proved that reasons not to start businesses and gender differences are related. Similarly, Reasons not to found employment are associated with literacy status of respondents. In this regard, the self employments or entrepreneurship propensity was tested that differed by gender differences. In addition, literacy rate proved that it is predictor of urban unemployment rate in which it inferred that as literacy rate increases by certain degree cause increases in urban unemployment rate other factors remain constant.

\section{Recommendation}

Based on the above finding the following points are suggested for urban policy makers.

Creating job opportunities to job seekers in order to mitigate urban unemployment rate. Tackling financial barriers to facilitate self employment. Emphasizing on entrepreneurship issues just to encourage private businesses. Giving priority for females since they are the largest proportion of job seekers thereby reduces urban unemployment. Giving adequate attention to educated who are the most predominant urban jobless that need to be considered so as to mitigate urban unemployment rate.

\section{Acknowledgements}

I would like to give my special thanks to Dr. Kassahun Asres, for his insightful coaching and support. Had it not been for his valuable advice this paper would not have appeared with its present form.

I would like to express my sincere appreciation to 
Statistics Agency for giving me all the necessary support to access raw data. I am also grateful to Central Statistics agency Office staff for their cooperation.

\section{References}

[1] A D, Tombolotutu, M A Djirimu, M Lutti and F Anggaddini. 2018. Impact of life expectancy, literacy rate, opened unemployment rate and gross domestic regional income per capita on poverty in the districts /city in central Sulawesi Province: IOP, Conference series, earth and environmental science. 157.012058.

[2] A. S, Bakare. 2011. The determinants of urban unemployment crisis in Nigeria: An econometric Analysis; journal of emerging trends in economics and management science (JETEEMS), 2, (3): 184-192.

[3] Ayres, Sarah. 2013. The high cost of youth Unemployment; Center for American Progress; April 5, 2013.

[4] Bicakova, Alena. 2010. Gender Unemployment Gaps: Evidence from the New EU Member States; Working Paper Series, 2010, vol. 20 (2), 41-97, CERGE-EI, WP 410.

[5] Broussard, C. Anne, Joseph, Alfred L. and Thompson, Marco. 2012. Stressors and Coping Strategies Used by Single Mothers Living in Poverty; Affilia: Journal of Women and Social Work 27 (2) 190-204 a 2012 SAGE Publications Reprints and permission: sagepub.com/journalsPermissions.nav DOI: 10.1177/0886109912443884 http: //affilia.sagepub.com

[6] Debele, Efa Tadesse. 2019. Paradoxes in urbanization and tragedy of the urban periphery; A sociological glance at periurban community surrounding Finfinne (Addis Ababa) City. Publisher; Scholars'press is a trademark of internation book market service 1td, member of OmniScriptum Publishing Group 17 meldrum street, Beau Bassin 71504, Mauritius, printed: ISBN: 978-613-8-82961-4, copyrightCEfa Tadesse Debele, copyright(C) Internation book market service ltd, member of OmniScriptum Publishing Group.

[7] Debele, Efa Tadesse and Imana, Gutema. Prospects and
Challenges of Urbanization on the Livelihood of Farming Community Surrounding Finfinne; American Research Journal of Humanities and Social Sciences; ISSN (Online): 2378-7031; Volume 3, Issue 1, 15 pages.

[8] Earle, J. S., Sakova, Z., 2000. Business start ups or disguised unemployment? Evidence on the character of self employment from transion economies; Labour economics 7 (2000) 575-601; www. elseviever.n1/locate /econbase.

[9] John Knight and Jinjun Xue. 2006. How high is urban unemployment in China?, journal of chinesse economic and Business Studies, 4: 2, 91-107, DOI: 10.1080/14765280600736833; https://doi.org/10.1080/14765280600736833.

[10] Lorenzini, J and Giugni, M (2010). Youth Coping with Unemployment: The role of social support.

[11] Meer, Peter van der. 2014. Gender, Unemployment and Subjective Well-Being: Why being unemployed is worse for men than for women; Social Indicators Research An International and Interdisciplinary; Journal for Quality-of-Life Measurement; ISSN 0303-8300; Soc Indic Res; DOI 10.1007/s11205-012-0207-5.

[12] Poschke, Markus. 2018. Wage employment, unemployment and self employment across the countries; International growth center; McGill University, CIREQ and IZA; F-32205ETH-1.

[13] Shita, A. and Dereje, M. 2018. Determinants of urban youth unemployment: Evidence from east Gojjam Zone, Ethiopia, Department of economics, Debre Markos University.

[14] US department of commerce, census bureau, current population survey, annual social and economic supplement, march 2018; digest of education statistics.

[15] Vipond, Joan. 1984. The intra-urban unemployment gradient: The influence of location on unemployment; urban studies (1984), 21, 377-388.

[16] Young, J. R. 2012. Underemployment in Urban and Rural America, 2005-2012; Carsery Institute, issue brief no. 55. fall 2012; www.carseyinstitute.unh.edu. 